Studies in African Linguistics

Volume 27, Number 1, Spring 1998

\title{
PROPERTIES OF APPLIED OBJECTS IN KISWAHILI AND KINDENDEULE*
}

\author{
Deo Ngonyani \\ Indiana University
}

\begin{abstract}
This paper examines objects which are licensed by the applicative affix in the Bantu languages of Kindendeule and Kiswahili. The data show that all verbs can take the applicative suffix deriving transitive verbs from intransitive verbs, and ditransitive verbs from transitive verbs. The applied objects can be interpreted as beneficiary, maleficiary, goal, instrument, reason, motive, ingredient, location, or theme. Only the agent role cannot be licensed by the applicative suffix. On the basis of object order, object marking, passivization, reciprocalization and reflexivization, the objects are classified into: (a) the benefactive type, (b) instrumental type, and (c) locative type.
\end{abstract}

\section{Introduction}

It is well known that the applicative suffix -il- in Bantu languages licenses an additional object. Most scholarly work in this area has focused on only two thematic roles of this object, the benefactive and the instrumental (cf. Alsina and Mchombo [1988], Baker [1988, 1992], Bresnan and Moshi [1990], Hoffman [1991], Marantz [1993]). However, there are several other thematic roles that the object may have, for example, recipient, goal, maleficiary, reason, purpose, and locative (cf. Ashton [1947], Kimenyi [1980], Trithart [1983], Bresnan and Moshi [1990]). My objective in this paper is to investigate and describe the properties associated with the various roles of applied objects, that is, to identify what kinds of objects are licensed by the applicative suffix and what properties they have. As I will show, applied objects do not all behave in the same way,

* I would like thank Tom Hinnebusch, Dominique Sportiche, Hilda Koopman, Chris Ehret, Nhlanhla Thwala, Robert Botne, and two anonymous reviewers for insightful discussions and comments. Some of the material was presented at the 26th Annual Conference on African Linguistics, March 1995, UCLA and appear in Ngonyani [1998]. 
depending on such syntactic phenomena as object order, passivization, object agreement, reciprocalization, and reflexivization. In Ngonyani [1998], I focused on establishing patterns of behavior of applied objects, showing that they fall into three groups. The present paper differs from the earlier paper in two respects. First, it provides a more comprehensive descrip-tion of the data, including thematic roles not previously considered. Second, it examines in greater depth applicatives derived from intransitive verbs.

The presentation is, on the whole, theory-neutral. I do not attempt to analyze the applicatives, ${ }^{1}$ rather I aim to generate descriptive generalizations which should be useful for work in different theoretical frameworks. Data for this paper come from Kiswahili (G.42 in Guthrie's [1967-71] classification) and Kindendeule, both of which I speak fluently. Kindendeule, my mother tongue, is a Southern Tanzanian Bantu language which is unclassified by Guthrie, but whose closest relative is Kingindo (P.14) [Ngonyani 1994].

This paper is organized into five sections. In Section 1, I present a brief review of the contributions of Bresnan and Moshi [1990] and Baker [1988, $1990,1992]$. I argue that these writers focus on limited data which obscures some problems inherent in their generalizations. Having reviewed these earlier studies, I then examine in Section 2 the object properties of applicatives derived from intransitive verbs. Section 3 investigates the properties of the ditransitive applicative. The examination of object properties leads to a taxonomy which I propose in Section 4. In Section 5 I present concluding remarks.

\section{Recent Studies}

Applicatives have been the focus of a number of recent studies [Bresnan and Moshi 1990; Baker 1988, 1992; Marantz 1993; Alsina and Mchombo 1988; Hoffman 1991]. The most significant of these with respect to the study of the syntactic properties of applied objects are Bresnan and Moshi [1990] and Baker $[1988,1990,1992]$. These will constitute the focus of discussion in this section.

2.2. Bresnan and Moshi [1990]. In their influential paper on object asymmetries in Bantu, Bresnan and Moshi [1990] differentiate symmetrical and asymmetrical object languages based on five syntactic diagnostics: passivization, object marking, reciprocalization, deletion of unspecified object, and cooccurrence of some of these features. In symmetrical object languages, such as Kichaga and Kinyarwanda, either object-direct or applied—can be the subject of the passive, can be marked on the verb, or can receive a reciprocal interpretation. They also permit combinations of these features. In addition, an unspecified object may be deleted. In asymmetrical object languages such as

${ }^{1}$ I have analyzed them within the Principles and Parameters framework in Ngonyani [1996]. I do not go into theoretical arguments regarding thematic roles or grammatical functions in the present paper because it is meant to be descriptive. 
Kiswahili and Chichewa, on the other hand, only the applied object can be the subject of the passive, can be marked on the verb, or can receive a reciprocal interpretation. Furthermore, combinations are not permitted, nor can an unspecified object be deleted. Their differentiation-via identification of these five parameters-of symmetrical and asymmetrical object languages is an invaluable contribution to the study of applicatives. However, they focus primarily on benefactive applicatives, alluding to other roles such as instrumental and locative without fully investigating their properties. Consider two cases, one involving the reciprocal interpretation of the direct object in the presence of an applied benefactive, the other the combination of reciprocal and passive.

In the first case, Bresnan and Moshi [1990] imply that, in both symmetrical and asymmetrical object languages, any applied object can be reciprocalized in the presence of a patient. However, in Kiswahili, an asymmetrical language, neither an instrumental (1a) nor a reason (1b) applied object can be reciprocalized. Hence, it is imperative for a complete understanding of the applicative to consider the thematic role of the applied object.

(1) Kiswahili
a. *wa-toto wa-li-zib-i-an-a
m-lango
2-child 2-PST-block-APP-REC-FV 3-door ${ }^{2}$
'The children used each other to block the door.'
b. *wa-li-ach-i-an-a ma-shamba
2-PST-leave-APP-REC-FV 6-farm
'They left the farms because of each other.'

With respect to the second case, the combining of reciprocal and passive, Bresnan and Moshi [1990:156] state: "Reciprocal verbs can be passivized in Kichaga... [but] This is impossible in Chichewa." In both the Kichaga and Chichewa examples they cite, given here in (2) and (3), respectively, the applied object is an instrument. However, if the applied object is a theme, for example, as in the Kiswahili sentence in (4), then the reciprocal can be passivized. That is, a reciprocal verb can be passivized in an asymmetrical language, but this depends crucially on the nature of the applied object.

2 Abbreviations

$\begin{array}{llllll}\text { AO } & \text { Applied Object } & \text { INF } & \text { Infinitive } & \text { PST } & \text { Past Tense } \\ \text { APP } & \text { Applicative } & \text { NEG } & \text { Negation } & \text { REC } & \text { Reciprocal } \\ \text { DO } & \text { Direct Object } & \text { PASS } & \text { Passive } & \text { REFL } & \text { Reflexive } \\ \text { FV } & \text { Final Vowel } & \text { PR } & \text { Present Tense } & \text { REL } & \text { Relative Marker }\end{array}$

Numbers in the glosses refer to noun classes. 
(2) Kichaga
shî -mîi
sh-î-kòr-í-àn-ò
(nà) wà-chàkà.

8-firebrand 8-PR-burn-APP-REC-FV by 2-Chaga

'Firebrands are being used by the Chagas to burn each other.'

\section{(3) Chichewa}

*mi-kŏndo i-na-mény-ér-an-ídw-á ndí á-lenje.

4-spears 4-REC PST-hit-APP-REC-PASS-FV by 2-hunters

'Spears were used by the hunters to hit each other.'

\section{(4) Kiswahili}

\section{zawadi zi-li-shind-an-i-w-a na wa-toto \\ 10.gift 10-PST-win-REC-APP-FV by 2-child \\ 'Prizes were competed for by children.'}

In addition to the type of thematic role the applied object may have, it is necessary to consider as well the relative order of the reciprocal and applicative affixes. The Kichaga example (2) has APP-REC order, while the Swahili example (4) has REC-APP order. These two facts, the difference in affix order and the passivization of the instrument or the theme, are related. This relationship needs to be explored for each applied object in both orders.

These data underscore two important points. First, different applicatives behave differently with respect to their syntactic properties. Hence, the properties of one kind of applied object cannot be assumed for another. Second, suffix ordering results in variable interpretation of the thematic role of the object. Consequently, a more comprehensive study of applied object properties is in order.

2.3. Baker [1988, 1990, 1992]. Like Bresnan and Moshi [1990], Baker [1988, 1990, 1992] discusses only three kinds of applicatives: benefactive, instrumental, and locative; hence, properties of other applicatives such as goal, maleficiary, and motive are neglected. More significant for the present study are two of Baker's claims. First, according to Baker, benefactives and locatives in Chichewa are both arguments of prepositions and, hence, should behave in a similar manner. As pointed out by Alsina and Mchombo [1990], the locative in Chichewa behaves very much like the instrumental applicative and not like benefactives. With locatives, as with instrumentals, both the direct and applied objects can be marked on the verb and can be passivized, which is not the case for benefactives.

Second, Baker claims that intransitive verbs cannot form benefactive applicatives. As Alsina and Mchombo [1990] have shown in Chichewa and as the Kiswahili example in (5) shows, this claim is incorrect. Intransitive verbs can 
take the applied suffix and, consequently, become transitive, in this case, with a beneficiary applied object.

(5) Kiswahili

Yesu a-li-wa-f-i-a wa-tu w-ote.

Jesus 1-PST-2-die-APP-FV 2-person 2-all

'Jesus died for all people.'

In this section, I have discussed how properties of applicatives have been handled in influential publications by Bresnan and Moshi [1990] and Baker $[1988,1990,1992]$. There have been many other studies in different theoretical frameworks. Within the lexical functional grammar framework, for example, Alsina and Mchombo [1990, 1993] have discussed benefactive, instrumental,and locative applicatives. Hoffman [1991] and Marantz [1993], within the Principles and Parameters framework, discuss benefactive and instrumental applicatives with some mention of locatives. In view of the fact that the applied suffix licenses a wide range of objects in terms of semantic roles and syntactic characteristics, a more detailed study of the syntactic properties of applicatives is required. This paper, therefore, addresses part of the problem by providing a wide range of data on applicatives. In the next two sections, I present object properties, first for transitive applicatives, then for ditransitive.

\section{Transitive applicatives from intransitive verbs}

The applicative increases the valency of the verb by one; hence, an intransitive verb becomes transitive, a transitive verb ditransitive. This section examines the properties of the applicatives in applied verbs derived from intransitive verbs. Data are taken from Kindendeule and Kiswahili, both asymmetrical object languages. The description will addresss three questions:

(i) What thematic roles may applied objects have in derived transitive applicatives?

(ii) What are the properties of these applied objects?

(iii) What patterns of syntactic behavior emerge?

For each of the thematic roles identified, the grammaticality of applied objects will be considered in terms of four syntactic contexts: object marking, passive, reflexive, and reciprocal.

3.1 Thematic roles. The applied object may occur with a broad range of thematic roles, the only one not licensed by the applicative being that of agent. Seven of these roles-benefactive, malefactive, goal, instrumental, reason, locative, and theme-will be considered. The sentences in (6), from Kindendeule, 
provide illustrative examples of use. Note that the applied suffix, /-il-/, varies in form, often appearing only as the final vowel of the verb. ${ }^{3}$

(6) Kindendeule

a. Yesu a-ki-ba-hwel-e ba-ndu b-oha

Jesus 1-PST-2-die-APP 2-person 2-all

'Jesus died for all people.'

b. mw-ana a-ki-m-butuk-i mayi-mu-ndu

1-child 1-PST-1-run-APP 1.mother-1-person

(Benefactive)

'She ran to her mother.'

c. a-ki-n-hyom- $\varepsilon \quad Y u d a$

1-PST-1-be angry-APP Judas

(Goal)

'He was angry with Judas.'

d. a-ki-tyang-i hi-latu

1-PST-walk-APP 8-shoe

'He walked with shoes.'

(Malefactive? Goal?)

e. a-ki-hyom- $\varepsilon$ ma-ligo

1-PST-be angry-APP 6-insults

(Instrumental)

'He got angry because of the insults.'

(Reason)

${ }^{3}$ Kindendeule realization of the applicative suffix:

Stem Vowels

$\mathrm{i}$
$\mathrm{e}$

Applicative suffix

-il-

-el-

$-\varepsilon l-$

-il-

In Kindendeule, a verb-final syllable with onset $/ 1 /$ is often deleted. The deleted final syllable bears the Low tone. The surface form of the verb exhibits two distinctive features: One is the verb-final vowel need not be /a/ or the subjunctive /e/. Secondly, the verb will have a High tone in the final syllable.

Kiswahili realization of the applicative affix:

\begin{tabular}{cclcc}
\multicolumn{2}{c}{ Stem Vowels } & & Applicative affix \\
$\mathrm{i}$ & $\mathrm{u}$ & $>$ & $-\mathrm{il-}$ \\
$\varepsilon$ & & $\mathrm{J}$ & $>$ & $-\varepsilon \mathrm{l}-$ \\
& $\mathrm{a}$ & & $>$ & -il-
\end{tabular}

Vowel final stems take $-i l$ - or $-\varepsilon l$ - as the suffix, but consonant final stems take $-i-$ or $-\varepsilon$ - as the suffix. 
f. Yesu a-ki-hwel-e ku-Golgota Jesus 1-PST-die-APP 15-Golgota

(Locative) 'Jesus died at Golgota.'

g. ba-ki-longel-e mi-haru

(Theme)

2-PST-talk-APP 4-issue

'They talked about the issues.'

Having identified a range of applied roles, we can now turn to a consideration of each of these roles in the four syntactic contexts: object marking, passive, reciprocal and reflexive.

3.2. Object Marking. Objects in Kindendeule and Kiswahili are realized in one of the following four ways: (i) as an NP without object marking; (ii) as an NP with object marking on the verb; (iii) as object marking on the verb without an overt lexical NP; and (iv) as $\varnothing$, i.e., with no NP and no object marking. These four patterns are summarized in (7), where the lexical object is indicated as NP and the object marker is indicated as OM, and $\varnothing$ stands for no object marker or lexical object. Examples from Kiswahili in (8) illustrate the four patterns. Note that the response in (8d) is an elliptical sentence [Ngonyani 1996]; there is neither object marking nor the object NP.

(7) a. $\varnothing-\mathrm{Vb} N \mathrm{NP}$

b. $\mathrm{OM}-\mathrm{Vb} \quad \mathrm{NP}$

c. $\mathrm{OM}-\mathrm{Vb} \varnothing$

d. $\varnothing-\mathrm{Vb} \varnothing$

(8) Kiswahili

a. m-geni a-li-let-a zawadi 'The guest brought a present.' 1-guest 1-PST-bring-FV 9.present

b. m-geni a-li-i-let-a zawadi 'The guest brought the present.'

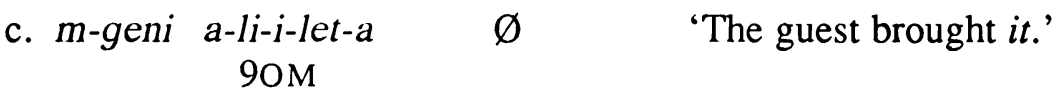

d. m-geni a-li-let-a u-jumbe? 'Did the guest bring a message?' 1-guest 1-PST-bring-FV 11-message ndiyo, a-li-let-a $\quad \varnothing \quad$ 'Yes, she did.' 
Object marking is determined by three semantic factors: pronominal function, definiteness and specificity, and animacy. The sentence in (8c) illustrates the pronominal function of the object marker: a verb is marked for the object but there is no lexical postverbal object NP. Identification of the object is based on features such as noun class and number which are coded in the object marker.

Object markers are often associated with definiteness and specificity, a wellknown feature in many languages (cf. Givon [1975] on Bantu; Sportiche [1993] on French and Dutch; Mahajan [1991] on Hindi; Morolong and Hyman [1977] on Sesotho). In Kiswahili and Kindendeule, too, definite objects trigger obligatory object agreement, as in (8b) above and in the examples in (9) below.

(9) Kiswahili

a. si-ku-ki-on-a ki-tabu h-iki

NEG.I-PST-7-see-FV 7-book this-7

'I didn't see this book.'

b. *si-ku-Ø-on-a ki-tabu h-iki

c. si-ku-ki-on-a ki-tabu

'I did not see the book.'

*'I did not see a book.'

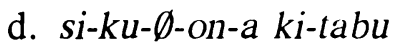

'I did not see a book.'

*'I did not see the book.'

The object in $(9 a, b)$ has a demonstrative, indicating it is a specific/definite NP. Only when the object is marked on the verb (9a) is the sentence grammatical because the definite object requires marking. Sentence (9b) has no object marker and, hence, is ungrammatical. Sentence (9c), since the object is marked on the verb, can only have a definite reading. In contrast, $(9 \mathrm{~d})$ has an indefinite reading as there is no object marking.

The third factor determining object marking is animacy. According to Hyman and Morolong [1977], for example, object marking is determined by the position of the object in the animacy hierarchy. On the basis of data from Sesotho they argued that:

An argument whose referent is higher in the following personal hierarchy, 1st $>$ 2nd $>$ 3rd human $>$ 3rd animate $>$ 3rd inanimate [incomplete] will tend to have more direct object properties than the argument whose referent is lower in this hierarchy. [Morolong and Hyman 1977: 202] 
In order to minimize the effects of animacy in the discussion of applicatives, I use inanimate applied objects. The three examples in (10) show that inanimate objects in Kiswahili can be marked on the verb.

(10) Kiswahili
a. a-li-i-f-i-a
nchi
(Beneficiary)
1-PST-9-die-APP-FV 9.country
'She died for the country.'

b. wa-li-zi-kimbil-i-a zawadi

2-PST-10-run-APP-FV 10.present

(Goal)

'They ran to the presents.'
c. wa-li-li-zungumz-i-a jambo h-ili (Theme)
2-PST-5-talk-APP-FV 5.matter this-5
'They discussed this matter.'

Not all objects can be marked on the verb. Objects of prepositions, as the examples in (11) illustrate, do not permit object marking. This is an important diagnostic feature for distinguishing applicative constructions from prepositional phrases.

\section{(11) Kiswahili}

a. ni-li-zungumz-a na Juma I-PST-speak-FV with Juma

'I spoke with Juma.'

b. *ni-li-m-zungumz-a na Juma

I-PST-1-speak-FV with Juma

Among the applied objects, notice that the beneficiary (10a), the goal (10b), and the theme (10c), have object marking on the verb. For instrumental applied objects, object marking is either marginal, as in Kiswahili (12a) or ungrammatical, as in Kindendeule (12b). For reason and locative objects, object marking is clearly ungrammatical in both languages (13-14).

(12) Instrumental

a. Kiswahili

?m-toto a-li-vi-tembel-e-a vi-atu

1-child 1-PST-8-walk-APP-FV 8-shoe

'The child walked with the shoes.' 
b. Kindendeule

*mw-ana a-ki-hi-tyang-i hi-latu

1-child 1-PST-8-walk-APP 8-shoe

'He walked with the shoes.'

(13) Kiswahili

$\begin{array}{ll}\text { a. *a-li-ya-kasirik-i-a } & \text { ma-tusi } \\ \text { 1-PST-6-be angry-APP-FV } & \text { 6-insult }\end{array}$

[Reason]

'The was angry at the insults.'
b. *a-li-pa-f-i-ar Golgota
1-PST-16-die-APP-FV Golgota
'He died on Golgota.'
[Locative]

(14) Kindendeule
a. *a-ki-ga-hyom- $\varepsilon$
ma-ligo
1-PST-6-get angry-APP 6-insult
[Reason]
'He got angry because of the insults.'
b. *Yesu a-ki-ku-hw-el-a ku-Golgota Jesus 1-PST-17-die-APP-FV 17-Golgota 'Jesus died at Golgota.'

[Locative]

3.3. Passive. Examples of passivization come only from Kiswahili because there is no passive construction in Kindendeule. The passive is made by (a) suffixing - $w$ - to the verb, (b) placing the logical object in the subject position, and (c) placing an optional 'by' phrase of the form na NP in postverbal position, as in (15).

(15) Kiswahili

a. m-zee a-li-wa-fundish-a wa-toto

1-old person 1-PST-2-teach-FV 2-child

'The elder taught the children.'

b. wa-toto wa-li-fundish-w-a na m-zee

2-child 2-PST-teach-PASS-FV by 1-old person

'The children were taught by the elder.'

Watoto 'children', the logical object of the sentences, functions as the object in the active sentence (15a), but is the subject of the passive sentence in (15b). Note that it determines subject agreement on the verb in the passive sentence. 
In the passivized applicative, the applied suffix precedes the passive suffix. As the examples in (16) illustrate, some applied objects, but not all, can be the subjects of the passive sentence.

(16) Kiswahili
a. wa-zee wa-li-imb-i-w-a na vi-jana
2-old person 2-PST-sing-APP-PASS-FV by 8-young people
(Benefactive)
'The elders were sung to by the young people.'

b. mama a-li-kimbil-i-w-a na mw-ana-e

1.mother 1-PST-run-APP-PASS-FV by 1-child-hers

'The mother was run to by her child'

c. Juma a-li-f-i-w-a na m-penzi w-ake

(Malefactive)

Juma 1-PST-die-APP-PASS-FV by 1 .friend 1 -his

'Juma was bereaved of his girlfriend.'

d. ??vi-atu vi-li-tembel-c-w-a na m-toto

8-shoe 8-PST-walk-APP-PASS-FV with 1-child

'Shoes were walked on by a child' ????

e. *ma-tusi ya-li-kasirik-i-w-a

na mw-enyekiti (Reason)

6-insult 6-PST-be angry-APP-PASS-FV by 1-chairperson

'Insults were got angry at by the chairperson.'

f. *Golgota pa-li-f-i-w-a na Yesu

Golgota 18-PST-die-APP-PASS-FV by Jesus

'Golgota was died at by Jesus.'

(Instrumental)

(Goal) 
benefactive, malefactive, and goal can be reflexivized, as in Kindendeule (17). A theme object, too, can be reflexivized, exemplified by the Kiswahili example in (18). I have not been able to construct reflexive sentences with instrumental, reason, and locative applicatives.

(17) Kindendeule
a. a-ki-ki-hin-i
1-PST-REFL-dance-APP
'He danced for himself.'
(Benefactive)
b. a-ki-ki-hyom-e
1-PST-REFL-be angry-APP
(Malefactive/Goal?)
'He got angry with himself.'
c. a-ki-ki-yinam-il-a
1-PST-REFL-Stoop-APP-FV
'He stooped to himself.'
(Goal)
(18) Kiswahili
a-li-ji-zungumz-i-a
1-PST-REFL-talk-APP-FV
(Theme)
'She/he talked about himself/herself.'

3.5. Reciprocal. The reciprocal in Kindendeule and Kiswahili has three features. First, it requires the verbal suffix -an-. Second, it must have a plural or conjoined subject, or a singular subject complemented by a comitative withphrase. Third, there is no lexical object. The Kindendeule examples in (19) contrast a non-reciprocal construct (19a) with three reciprocal forms: a conjoined NP subject (19b), a plural subject (19c), and a singular subject with a withphrase in postverbal position (19d).

(19) Kindendeule
a. mw-ana a-ki-n-lig-a $n-g \varepsilon n i$
1-child 1-PST-1-insult-FV 1-guest
'The child insulted the guest.'

b. mw-ana na n-geni ba-ki-lig-an-a

1-child and 1-guest 2-PST-insult-REC-FV

'The child and the guest insulted each other.'

c. ba-ndu ba-ki-lig-an-a

2-person 2-PST-insult-REC-FV

'People insulted each other.' 

d. mw-ana a-ki-lig-an-a na n-geni
1 -child 1-PST-insult-REC-FV with 1 -guest
'The child and the guest insulted each other.'

Benefactive, goal, and malefactive applied objects all occur readily with the reciprocal (20). Instrumental, reason, and locative sentences are impossible to construct. An applied theme object can also occur in the reciprocal construction, though it is easier to construct an example in Kiswahili, illustrated in (21). Notice in all of these examples that the order of the suffixes is APP-REC.

(20) Kindendeule
a. ba-ki-hin-il-an-a
2-PST-dance-APP-REC-FV
'They danced for each other.'
b. ba-ki-hyom-el-an-a
2-PST-be angry-APP-REC-FV
'They were angry at each other.'
(Malefactive, goal?)
c. ba-ki-butuk-il-an-a
2-PST-run-APP-REC-FV
'They ran to each other.'
(Benefactive) 
(22) A summary of object properties in monotransitive applicatives

\begin{tabular}{|l|c|c|c|c||c|c||c|}
\hline & BEN & GOAL & MAL & THEM & INST & REAS & LOC \\
\hline Obj Marking & $\sqrt{ }$ & $\sqrt{ }$ & $\sqrt{ }$ & $\sqrt{ }$ & $?$ & $*$ & $\sqrt{ }$ \\
\hline Passive4 & $\sqrt{ }$ & $\sqrt{ }$ & $\sqrt{ }$ & $\sqrt{ }$ & $?$ & $*$ & $\sqrt{ }$ \\
\hline Reflexive & $\sqrt{ }$ & $\sqrt{ }$ & $\sqrt{ }$ & $\sqrt{ }$ & & & $*$
\end{tabular}

Key to Judgments

\begin{tabular}{|c|c|}
\hline$\sqrt{ }$ & Grammatical \\
\hline$?$ & Marginal \\
\hline * & Ungrammatical \\
\hline & Unable to construct examples \\
\hline
\end{tabular}

object marking and passivization but not reflexivization or reciprocalization.

Having examined transitive applicatives, we can now turn to ditransitive applicatives and investigate the same properties as well as object order, which is specific to double object constructions.

\section{Ditransitive applicatives}

Ditransitive applicatives are more complex than simple transitives because they involve a relationship not only between the object and the verb, but also between the two objects, the patient, or theme, and the applied object. I will refer to the theme/patient object as the direct object. As already noted, these objects do not relate in the same way to the verb.

In this section, both direct and applied objects are considered in terms of their potential linear order, their potential to be object marked or passivized, and their potential to receive a reciprocal interpretation or to reflexivize.

4.1. Linear order of objects. The order of the direct and applied objects depends on two factors: the thematic role of the applied object and whether or not there is object-marking on the verb. Cases without object marking will be described first. To preclude the effects of animacy, I use either both animate or both inanimate objects.

4.1.1. V AO DO. The order applied object+direct object, as shown by the examples in (23), is only grammatical when the applied object is a benefactive, a goal, or a malefactive. Instrumental, motive, and ingredient applied objects are

${ }^{4}$ In Kiswahili only because Kindendeule does not have a passive construction. 
extremely marginal and awkward, while a locative applied object cannot precede the direct object at all.

(23) Kiswahili

a. Juma a-li-chor-e-a ma-gazeti picha 5

(Benefactive)

Juma 1-PST-draw-APP-FV 6-paper 10.picture

'Juma drew pictures for papers.'

b. m-sichana a-li-sukum-i-a kuku ma-jongoo

1-girl 1-PST-push-APP-FV 2.chicken 6-milipede

'The girl pushed millipedes towards chickens.'

c. fundi a-li-kat-i-a m-taa u-meme (Malefactive)

1.technician 1-PST-cut-APP-FV 3-neighborhood 11-power

'The technician cut power to the neighborhood.'

d. ?? wa-toto wa-li-vunj-i-a ma-we ch-ungu

(Instrumental)

2-child 2-PST-break-APP 6-rock 7-pot

'The children broke the pot with rocks.'

e. ??wa-windaji wa-li-wind-i-a pesa ndovu

2-hunter 2-PST-hunt-APP-FV 10.money 9.elephant

'The hunters hunted the elephant for money.'

f. ?m-pishi a-li-ung-i-a pilipili nyama

1-cook 1-PST-season-APP-FV 10.pepper 9.meat

(Goal)

'The cook seasoned the meat with pepper.'

g. *wa-teja wa-li-l-i-a ofisi-ni ch-akula

2-customer 2-PST-eat-APP-FV 9.office-LOC 7-food

'The customers ate food in the office.'

(Ingredient)

Wh-questions, in which the question word is usually in-situ in Kiswahili, might be expected to provide some evidence for marginal cases such as the instrumental. In (24a), for example, nini questions the instrument and must precede the direct object, as (24b) indicates. However, the examples in (25) show that the order of object constituents in questions is not determined by the objects, but rather, by the question word, which must follow the verb immediately.

5 In this context, the applied object magazeti (newspapers) is non-specific, non-definite. 
(24) Kiswahili
a. wa-toto wa-li-vunj-i-a nini ch-ungu?
2-child 2-PST-break-APP-FV what 7-pot
'What did the children break the pot with?'
b. *wa-toto wa-li-vunj-i-a ch-ungu nini?
2-child 2-PST-break-APP-FV 7-pot what
'What did the children break the pot with?'

(25) a. wa-toto wa-li-vunj-i-a nini ma-we?

2-child 2-PST-break-APP-FV what 6-rock

'What did the children break with the rocks?'

b. *wa-toto wa-li-vunj-i-a ma-we nini?

2-child 2-PST-break-APP-FV 6-rock what

'What did the children break with the rocks?'

3.1.2. V DO AO. The order direct object+applied object provides almost the reverse results from those observed above for the applied+direct order. In this case, only the locative applied object $(26 \mathrm{~g})$ results in a grammatical sentence, while benefactive (26a), goal (26b), and malefactive (26c) are all ungrammatical. Again, instrumental, reason, and ingredient are all marginal. In Cimwiini, a Kiswahili dialect located on the northern end of the Kiswahili dialect continuum, Kisserbeth and Abasheikh [1977] report that the instrumental applied object cannot co-occur in postverbal position with a direct object.

(26) Kiswahili6 Juma 1-PST-draw-APP-FV 10.picture 6-paper 'Juma drew pictures for papers.'
a. *Juma a-li-chor-e-a picha ma-gazeti
b. *m-sichana a-li-sukum-i-a jongoo kuku 1-girl 1-PST-push-APP-FV 5.millipede 2.chiken 'The girl pushed a millipede towards chickens.'
(Benefactive)
c. *fundi a-li-kat-i-a u-meme m-taa 1.technician 1-PST-cut-APP-FV 11-power 3-neighborhood 'The technician cut power to the neighborhood.'

\footnotetext{
${ }^{6}$ All grammaticality judgments are based on the intended meaning indicated after the glosses. Other possible readings will be referred to when they are relevant to the discussion. For example, (26b) is grammatical if the goal is the millipede. But what is relevant here is "towards the chickens".
} 
d. ??wa-toto wa-li-vunj-i-a ch-ungu ma-we

2-child 2-PST-break-APP-FV 7-pot 6-rock

'The children broke the pot with rocks.'

e. ?? wa-windaji wa-li-wind-i-a ndovu pesa

(Reason)

2-hunter 2-PST-hunt-APP-FV 9.elephant 10.money

'The hunters hunted the elephant for money.'

f. ??m-pishi a-li-ung-i-a nyama pilipili

1-cook 1-PST-season-APP-FV 9.meat 10.pepper

(Instrumental)

"The cook seasoned the meat with pepper.'

g. wa-teja wa-li-l-i-a ch-akula ofisi-ni 2-customer 2-PST-eat-APP-FV 7-food 9.office-LOC 'The customers ate food in the office.'

(Ingredient)

(Locative)

The marginal nature of instrumental, reason, and ingredient applicatives in both types of word order shows crucially that the two objects cannot be realized together in post-verbal position when the applied object has one of these roles. Nevertheless, there are two strategies that permit the co-occurrence of instrumental, reason, and ingredient applied objects and a direct object: object movement and object marking. In (27), the instrument has been topicalized and only the direct object occurs in post-verbal position. These applied objects can also occur in relative clauses, such as the infinitival and finite relatives in (28).

(27) Kiswahili

ki-su , wa-li-kat-i-a nyama

7-knife 2-PST-cut-APP-FV 9.meat

'The knife, they cut the meat with (it).'

(28) a. ki-tu ch-a ku-kat-i-a nyama 7-thing 7-of INF-cut-APP-FV 9.meat

'A thing to cut meat with.'

b. ki-su amba-cho a-li-kat-i-a nyama 7-knife which-7REL 1-PST-cut-APP-FV 9.meat 'The knife with which she cut meat.'

The other way of realizing instrumental applicatives is by removing the direct object, which is marked, instead, on the verb. Thus, in Kindendeule, for example, the direct object nkota 'sugar cane' can be marked as an object on the verb (29a), but cannot, at the same time, occur in post-verbal position (29b,c). 
(29) Kindendeule
a. ba-ki-u-heket-e ki-hembe
2-PST-3-cut-APP 7-knife
'They cut it (the sugar cane) with a knife.'
b. ?ba-ki-u-heket-e ki-hembe n-kota
2-PST-3-cut-APP 7-knife 3-sugar cane
'They cut sugar cane with a knife.'
2-PST-3-cut-APP 3-sugar cane 7-knife
'They cut sugar cane with a knife.'
c. ?ba-ki-u-heket-e n-kota ki-hembe

Two important observations emerge from these facts. First, benefactive, goal, malefactive, and locative applied objects can co-occur in postverbal position with a direct object; instrumental, reason, and ingredient applied objects cannot. Second, benefactive, goal, and malefactive applied objects must precede the direct object; the locative applied object must follow it. Instrumental, reason, and ingredient applied objects can only co-occur with a direct object when the direct object is a pronominal marked on the verb or by moving one object to pre-verbal position.

4.2. Object order with object marking. The form and functions of object marking in Kindendeule and Kiswahili were described previously in \$3.2. In this section the relative positions of the applied object and the direct object will be described. First, I will consider examples in which the applied object is marked on the verb, and then I will look at examples in which the direct object is marked.

4.2.1. Object marking of the applied object. Marking the applied object on the verb, as the examples in (30) from Kiswahili show (the applied object with its corresponding object marker are underlined), produces similar results to those noted above for object order, with two important differences. First, as noted above, benefactives, goals, and malefactives are all grammatical. On the other hand, instrumental, purpose, ingredient, and locative applied objects are ungrammatical in this context.

(30) Kiswahili
a. Juma a-li-wa-let-e-a
wa-toto mw-alimu
Juma 1-PST-1-bring-APP-FV 2-child
'Juma bought a teacher for the child'
1-teacher

(Benefactive) 
b. m-sichana a-li-wa-sukum-i-a kuku jongoo 1-girl 1-PST-2-push-APP-FV 2.chicken 5.millipede (Goal)

'The girl pushed a millipede towards the chickens.'

c. fundi a-li-i-kat-i-a mi-taa u-meme (Malefactive) 1.technician 1-PST-4-cut-APP-FV 4-neighborhood 11-power 'The technician cut power to the neighborhoods.'

d. *wa-toto wa-li-ya-vunj-i-a ma-we ch-ungu 2-child 2-PST-6-break-APP-FV 6-rock 7-pot

'The children broke the pot with rocks.'

e. *wa-windaji wa-li-zi-wind-i-a ndovu pesa (Purpose) 2-hunter 2-PST-10-hunt-APP-FV 9.elephant 10.money 'The hunters hunted the elephant for money.'

f. *wa-li-zi-ung-i-a pilipili nyama (Ingredient) 2-PST-10-season-APP-FV 10.pepper 9.meat 'They seasoned the meat with pepper.'

g. *wa-teja wa-li-pa-l-i-a ch-akula ofisi-ni
2-customer 2-PST-16-eat-APP-FV 7-food office-LOC (Locative) 'The customers ate food in the office.'

Second, in both Kindendeule and Kiswahili, object marking permits either ordering of the two objects, that is, either applied+direct or direct+applied, as in (31).

(31) Kiswahili
a. a-li-wa-let-e-a
wa-toto zawadi
V AO DO
1-PST-2-bring-APP-FV 2-child 10.present
'She brought presents for the children.'
b. a-li-wa-let-e-a
zawadi wa-toto
$\mathrm{V}$ DO AO
1-PST-2-bring-APP-FV 10.present 2-child
'She brought presents for the children.'

4.2.2. Object marking of the direct object. Object marking of the direct object is grammatical only for the locative, as illustrated by the examples in (32). Benefactive, goal, malefactive, and ingredient do not permit the direct object to be marked on the verb. Instrumental and motive are marginal. These results are the same regardless of order of the two objects. 
(32) Kiswahili
a. *Juma a-li- $\underline{m}-$ let-e-a mw-alimu wa-toto Juma 1-PST-1-bring-APP-FV 1-teacher 2-child
'Juma bought the teacher for the children.'

(Benefactive)

$\begin{array}{cll}\text { b. *M-sichana a-li- } \underline{m} \text {-sukum-i-a } & \text { jongoo } k u k u \\ \text { 1-girl 1-PST-1-push-APP-FV } & \text { 1.millipede 2.chicken }\end{array}$

'The girl pushed a millipede towards the chickens.'

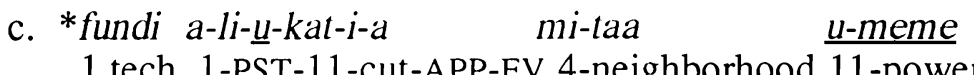

(Malefactive) 1.tech. 1-PST-11-cut-APP-FV 4-neighborhood 11-power

'The technician cut power to the neighborhoods.'

d. ?? wa-toto wa-li-ki-vunj-i-a ch-ungu ma-we

2-child 2-PST-7-break-APP-FV 6-rock 7-pot

'The children broke the pot with rocks.'

$(\mathrm{Goal})^{7}$

\author{
(Malefacive)
}

e. ?? wa-windaji wa-li-wa-wind-i-a ndovu pesa

2-hunter 2-PST-2-hunt-APP-FV 2.elephant 10.money

'The hunters hunted the elephant for money.'

f. *wa-li-i-ung-i-a nyama pilipili

(Ingredient)

2-PST-10-season-APP-FV 9.meat 10.pepper

(Instrumental)

'They seasoned the meat with pepper.'
g. wa-teja wa-li-ki-l-i-a ch-akula ofisi-ni 2-customer 2-PST-7-eat-APP-FV 7-food office-LOC 'The customers ate food in the office.'

(Motive)

(Locative)

Recall that there is a restriction on the post-verbal realization of both objects in instrumental, reason, and ingredient applicatives. To accommodate this restriction, I have constructed sentences with only one postverbal object and a topicalized object marked on the verb. In (33), instrument, purpose, and ingredient applied objects have been topicalized and marked on the verb. All three cases are ungrammatical. Hence, these applicatives cannot be marked on the verb even when the direct object is the only object appearing in postverbal position.

In (34), the direct object has been topicalized and marked on the verb, while the applied object is the only post-verbal object. These are all grammatical; hence, it is possible to mark a topicalized direct object with an instrument, motive, or ingredient applied object.

7 Grammatical for the meaning "the girl pushed chickens towards the millipede". 
(33) Kiswahili
a. *ma-we wa-toto wa-li-ya-vunj-i-a ch-ungu
6-rock 2-child 2-PST-6-break-APP-FV 7-pot
'The rocks, the children broke the pot with them.'
(Instrumental)

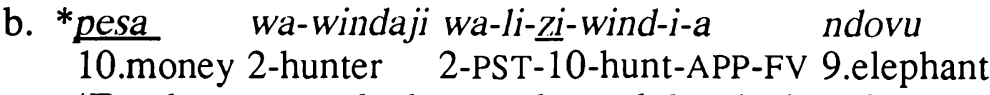
'For the money, the hunters hunted the elephant.'
c. *pilipili wa-li-zi-ung-i-a nyama
10.pepper 2-PST-10-season-APP-FV 9.meat
'They seasoned the meat with pepper.'
(Ingredient)
(Purpose)

(34) a. ch-ungu wa-toto wa-li-ki-vunj-i-a ma-we

7-pot 2-child 2-PST-7-break-APP-FV 6-rock

'The pot, the children broke it with rocks.'

b. ndovu wa-windaji wa-li-wa-wind-i-a pesa

(Motive)

2.elephant 2-hunter 2-PST-2-hunt-APP-FV 10.money

'The hunters hunted the elephant for money.'

$\begin{array}{lll}\text { c. } \frac{\text { nyama }}{9 . m e a t} & \text { wa-li-i-ung-i-a } & \text { pilipili } \\ \text { 2-PST-10-season-APP-FV 10.pepper }\end{array}$

(Instrumental)

'The meat they seasoned it with pepper.'

In sum, object marking is possible for applied objects only in benefactive, maleficiary, and goal applicatives. It is possible for direct objects only in instrumental, reason, ingredient, and locative applicatives. Marking of the direct object in instrumental, reason, or ingredient applicatives is only possible when the applied object occurs as the only object in postverbal position. These results are consistent with the findings on object order in which we saw that, for benefactive, goal, and malefactive applicatives, the applied object precedes the direct object while for the locative applicative, the applied object follows the direct object.

4.3. Passive. The structural properties of the passive construction were outlined previously in \$3.3. We saw that, for simple transitive applicatives, benefactive, goal, and malefactive applied objects can be passivized, while the instrumental is marginal and the reason and locative ungrammatical. In ditransitive applicatives, we find similar results.

4.3.1. Passivization of applied objects. The Kiswahili examples in (34) illustrate passivized applied objects that have been promoted to subject position. 
Benefactive, goal, malefactive, and locative applied objects can passivize. Purpose and ingredient applied objects cannot. Passivization of the instrument applied object is marginal.

(34) Kiswahili
a. wa-toto wa-li-let-e-w-a
$m w$-alimu
(Benefactive)
2-child 1-PST-bring-APP-PASS-FV 1-teacher
'The children had a teacher brought for them.'

b. kuku wa-li-sukum-i-w-a jongoo

2.chicken 2-PST-push-APP-PASS-FV 5.millipede

(Goal)

'The chickens had a millipede pushed towards them.'

c. mi-taa i-li-kat-i-w-a u-meme

4-neighborhood 4-PST-cut-APP-PASS-FV 11-power

(Malefactive)

'The neighborhoods had their power cut

(i.e., at the expense of the neighborhoods).'

d. ?ma-we ya-li-vunj-i-w-a vy-ungu

6-rock 6-PST-break-APP-PASS-FV 8-pot

(Instrumental)

'The rocks were used to break pots with.'

e. *pesa zi-li-wind-i-w-a ndovu

10.money 10-PST-hunt-APP-PASS-FV 9.elephant

(Purpose)

'Elephants were hunted for money.'

f. *pilipili zi-li-ung-i-w-a nyama

10.pepper 10-PST-season-APP-PASS-FV 9meat

'Peppers was used to season the meat.'

g. ofisi-ni pa-li-l-i-w-a ch-akula office-LOC 16-PST-eat-APP-PASS-FV 7-food 'In the office was eaten food.'

3.3.2. Passivization of the direct object. The examples in (35) contain the same lexical items as those in (34) above, but here the direct object has been passivized. With benefactive, goal, and malefactive applied objects, the direct object cannot passivize. However, with a locative applied object, it can. With instrument, motive, and ingredient applied objects, passivization is marginally grammatical. 
(35) Kiswahili
a. *mw-alimu a-li-let-e-w-a
wa-toto
(Benefactive)
1-teacher 1-PST-bring-APP-PASS-FV 2-child
'The teacher was brought for the child.'
$\begin{array}{ccl}\text { b. }{ }^{*} \text { jongoo } & \text { a-li-sukum-i-w-a } & k u k u \\ \text { 1.milipede } & 1 \text {-PST-push-APP-PASS-FV } & 2 . c h i c k e n\end{array}$
(Goal)
'The millipede was pushed towards the chicken.'
c.
$\begin{array}{ll}\text { *u-meme u-li-kat-i-w-a } & \text { mi-taa } \\ \text { 11-electricity 11-PST-cut-APP-PASS-FV 4-neighborhood } & \end{array}$
(Malefactive)
'Power was cut from the neighborhoods.'

d. ?ch-ungu ki-li-vunj-i-w-a ma-we

7-pot 7-PST-break-APP-PASS-FV 6-rock

'The pot was broken with rocks.'

e. ?ndovu wa-li-wind-i-w-a pesa

(Motive)

2.elephant 2-PST-hunt-APP-PASS-FV 10.money

'Elephants were hunted for money.'

f. ?nyama i-li-ung-i-w-a

pilipili

9.meat 9-PST-season-APP-PASS-FV 10.pepper

(Instrumental)

'The meat was seasoned with salt.'

g. ch-akula ki-li-l-i-w-a ofisi-ni

7-food 7-PST-eat-APP-PASS-FV 9.office-LOC

(Locative)

'The food was eaten in the office.'

4.4. Reciprocalization. Objects in applicative constructions do not reciprocalize freely. However, the pattern is entirely parallel to the those observed for object order, object agreement, and passivization. That is, benefactive, goal, and malefactive pattern together, as do instrument and reason. The locative, where it is possible to construct examples, is separate.

4.4.1. Reciprocal interpretation of the applied object. In the Kindendeule examples in (36), the reciprocalized (and, therefore, missing) object is the applied object. Suffix order is APP+REC. Benefactive, goal, and malefactive applied objects may reciprocalize; instrument and motive applied objects may not. 


\section{(36) Kindendeule}
a. ba-cikana ba-ki-let-el-an-a ba-congolo
2-girl 2-PST-bring-APP-REC-FV 2-boy
'The girls brought boys for each other.'
b. ba-chongslo ba-ki-kang-il-an-a ma-gongols 2-boy 2-PST-push-APP-REC-FV 6-millipede

(Goal)

'The boys pushed millipedes to each other.'

c. ba-ki-yib-il-an-a ba-congols

2-PST-steal-APP-REC-FV 2-boy

'They stole boys from each other.'

d. *ba-ki-hib-il-an-a n-dyango

(Instrumental)

2-PST-close-APP-REC-FV 3-door

(Malefactive)

'They used each other to block the door.'

e. *ba-ki-lek-cl-an-a mi-gonda

(Reason)

2-PST-leave-APP-REC-FV 4-farm

'They left the farms because of each other.'

4.4.2. Reciprocalization of direct objects. Reciprocalizing the direct object of the examples in (36) with suffix order APP+REC is ungrammatical in all cases, as shown in (37).

(37) Kindendeule
a. *ba-cikana ba-ki-let-el-an-a
ba-congolo
(Benefactive) 2-girl 2-PST-bring-APP-REC-FV 2-boy

'The girls brought each other for the boys.'

b. *ba-chongslo ba-ki-kang-il-an-a ma-gongols 2-boy 2-PST-push-APP-REC-FV 6-millipede 'The boys pushed each other to the millipedes.'

(Goal)

c. *ba-ki-yib-il-an-a ba-congolo

(Malefactive) 2-PST-steal-APP-REC-FV 2-boy

'They stole each other from the boys.'

d. *ba-ki-hib-il-an-a n-dyango

2-PST-close-APP-REC-FV 3-door

(Instrumental)

'They blocked each other with the door.' 


\section{e. *ba-ki-lek-cl-an-a mi-gonda \\ 2-PST-leave-APP-REC-FV 4-farm}

(Reason)

'They left the farms because of each other.'

Direct objects can be reciprocalized, in some cases, when the order of the verb suffixes is reversed, hence, REC+APP. The direct object, as the examples in (38) show, can be reciprocalized when it co-occurs with instrumental, motive or locative applicatives but not when it co-occurs with benefactive or goal applicatives.

(38) Kindendeule
a. *ba-ki-kom-an-i lu-kolo
2-PST-kill-REC-APP 11-clan
(Benefactive)
'They killed each other for the clan.'
b. *ba-ki-kang-an-i ma-gongolo
2-PST-push-REC-APP 6-milipede
'They pushed each other to the milipedes.'
(Goal)
c. ba-ki-tem-an-i ki-hembe
2-PST-cut-REC-APP 7-knife
(Instrumental)
'They cut each other with a knife.'
d. ba-ki-lek-an-i mi-gonda
(Reason)
2-PST-leave-REC-APP 4-farm
'They left each other because of farms.'
e. ba-ki-tem-an-i ku-ki-hinja
(Locative)
2-PST-cut-REC-APP 17-7-kitchen
'They cut each other in the kitchen.'

In sum, the applied object may be reciprocalized if it is a beneficiary, goal or maleficiary. In this case, the order of verb suffixes must be APP+REC. With the reverse order, REC+APP, as seen in (38), the reciprocal reading applies to the direct object, but only in cases in which the applied object is instrument, motive, or locative. The facts regarding reciprocals are the same in Kindendeule and in Kiswahili.

\section{A classification of applicatives}

So far I have shown that the applied objects behave differently depending on their thematic role. While all the applied objects seem to be licensed by the same applicative suffix, they do not behave the same way; they pattern into three sets. 
These patterns and the properties of applied objects they are based on are summarized in the table in (39). The table summarizes the data for both Kindendeule and Kiswahili. The only exception here is the passive since, as noted previously, Kindendeule does not have a passive.

(39) Object properties in applicative constructions 8

\begin{tabular}{|ll|c|c|c||c|c||c|}
\cline { 3 - 7 } \multicolumn{1}{c|}{} & & BEN & GOAL & MAL & INST & MOT & LOC \\
\hline \multirow{2}{*}{ OBJ. ORDER } & AO DO & $\sqrt{ }$ & $\sqrt{ }$ & $\sqrt{ }$ & $*$ & $*$ & $*$ \\
\cline { 3 - 8 } & DO AO & $*$ & $*$ & $*$ & $?$ & $\sqrt{ }$ & $\sqrt{ }$ \\
\hline \multirow{2}{*}{ OBJ. MARK } & AO & $\sqrt{ }$ & $\sqrt{ }$ & $\sqrt{ }$ & $?$ & $?$ & $*$ \\
\cline { 3 - 8 } & DO & $*$ & $*$ & $*$ & $? \sqrt{ }$ & $\sqrt{ }$ & $\sqrt{ }$ \\
\hline \multirow{2}{*}{ PASS } & AO & $\sqrt{ }$ & $\sqrt{ }$ & $\sqrt{ }$ & $?$ & $?$ & $\sqrt{ }$ \\
\hline \multirow{2}{*}{ REC } & DO & $*$ & $*$ & $*$ & $? \sqrt{ }$ & $\sqrt{ }$ & $\sqrt{ }$ \\
\hline \multirow{2}{*}{ REFL } & AO & $\sqrt{ }$ & $\sqrt{ }$ & $\sqrt{ }$ & $*$ & $*$ & $*$ \\
\cline { 3 - 8 } & DO & $*$ & $*$ & $*$ & $\sqrt{ }$ & $\sqrt{ }$ & $\sqrt{ }$ \\
\hline & AO & $\sqrt{ }$ & $\sqrt{ }$ & $\sqrt{ }$ & $*$ & $*$ & $*$ \\
\hline & DO & $*$ & $*$ & $*$ & $\sqrt{ }$ & $\sqrt{ }$ & $\sqrt{ }$ \\
\hline
\end{tabular}

Key to Judgments

\begin{tabular}{|c|l}
\hline$\sqrt{ }$ & Grammatical \\
\hline$?$ & Marginal \\
\cline { 1 - 1 } & Ungrammatical \\
\hline
\end{tabular}

The following patterns of applicative behavior emerge:

(a) Benefactive, goal, and malefactive pattern together. In these cases, the applied object precedes the direct object, it can be marked on the verb, it can passivize, and it can be be reciprocalized. The benefactive can be con-sidered prototypical of this set.

(b) Instrumental, motive, and ingredient applicatives pattern together with a few minor differences found in behavior. Unlike benefactive, goal, and malefactive applied objects, instrument, motive, and ingredient applied objects cannot be object marked, nor can they passivize or receive a

8 Abbreviations for the table:

AO applied object

BEN benefactive

DO direct object

INST instrumental
LOC locative

MAL malefactive

MOT motive

OBJ object
OM object marking

PASS passivization

REC reciprocalization

REFL reflexivization 
reciprocal interpretation. Rather, it is the direct object co-occurring with these applicatives that can receive a reciprocal interpretation. The instrumental can be considered prototypical of this set.

(c) The locative applicative patterns by itself. A locative applied object must follow a direct object. It can passivize but it cannot be marked on the verb. In addition, the direct object can be marked on the verb and can passivize.

\section{Conclusion}

In this paper, I have provided a comprehensive examination of object properties of applicative constructions in an attempt to answer three questions about applicative behavior: What applied objects are licensed by the applicative suffix?; What syntactic properties do objects in applicative constructions have?; What syntactic patterns emerge from these properties?

The applicative suffix functions to license an additional object, the applied object. Thus, it makes intransitive verbs transitive, transitive verbs ditransitive. Data on applicatives in Kindendeule and Kiswahili have shown that a wide range of thematic roles are licensed as applied objects. Whether in transitive or ditransitive constructions, properties of applied objects of the same type were found to be the same. What is significant about the findings here is that applied objects fall into three sets: (1) benefactive, goal, and malefactive; (2) instrument, motive (reason and purpose) and ingredient; and (c) locative.

In the course of examining the properties of the applicatives, I have shown that some of the properties involve interaction with the order of verbal suffixes. Thus, APP+REC order permits benefactive type applicatives to be reciprocalized, but not reciprocalization of the direct object. REC+APP order, on the other hand, permits only reciprocalization of direct objects and not applied objects. This suggests that the internal structure of the verb is accessible to syntax, a point worth investigating further.

\section{REFERENCES}

Alsina, Alex and Sam Mchombo. 1990. "The syntax of applicatives in Chichewa: Problems for a theta theoretic asymmetry." Natural Language and Linguistic Theory 8: 493-506.

Alsina, Alex and Sam Mchombo. 1993. "Object asymmetries and the Chichewa applicative construction." In S. Mchombo (ed.), Theoretical Aspects of Bantu Grammar, pp. 17-45. Stanford: Center for the Study of Language and Information. 
Ashton, Ethel O. 1947. Swahili Grammar. London: Longmans, Green and Co.

Baker, Mark. 1988. Incorporation: A Theory of Grammatical Function Changing. Chicago: Chicago University Press.

Baker, Mark. 1990. "Elements of a typology of applicatives in Bantu." In J. Hutchison and V. Manfredi (eds.), Current Approaches to African Linguistics 7, pp. 111-124. Dordrecht: Foris.

Baker, Mark. 1992. "Thematic conditions on syntactic structures: Evidence from locative applicatives." In I. M. Roca (ed.), Thematic Structure: Its Role and Grammar, pp. 23-46. New York: Foris.

Bresnan, Joan and Lioba Moshi. 1990. "Object asymmetries in comparative Bantu." Linguistic Inquiry 21, 2: 147-185.

Givon, Talmy. 1972. Studies in Chibemba and Bantu Grammar. Studies in African Linguistics, supp. 3.

Guthrie, Malcom. 1967-71. Comparative Bantu Vol. I-IV. Farnborough: Gregg Press.

Hoffman, Mika C. 1991. "The syntax of argument-structure changing morphology." Ph.D. dissertation, MIT.

Kimenyi, Alexandre. 1980. A Relational Grammar of Kinyarwanda. Berkeley: University of California Press.

Kisserberth, Charles and Mohammed Abasheikh. 1977. "The object relationship in Chi-mwi:ni, a Bantu language." In P. Cole and J. N. Sadock (eds.), Syntax and Semantics: Grammatical Relations 8, pp. 179-218. New York: Academic Press.

Mahajan, Anoop. 1991. "Clitic doubling, object agreement and specificity." Proceedings of the North Eastern Linguistics Society Annual Meeting 21:263-277.

Marantz, Alec. 1993. "Implications of the asymmetries in double object constructions." In S. A. Mchombo (ed.), Theoretical Aspects of Bantu Grammar, pp. 113-150. Stanford: Center for the Study of Language and Information. 
Morolong, Malilo and Larry Hyman. 1977. "Animacy, objects, and clitics in Sesotho." Studies in African Linguistics 8: 199-218.

Ngonyani, Deo. 1998. "Towards a typology of applicatives in Bantu." In I. Maddieson and T. Hinnebusch (eds.), Language History and Linguistic Description in Africa, pp. 248-257. Trenton, N.J.: Africa World Press.

Ngonyani, Deo. 1997. "The constituent structure of Kindendeule applicatives." Paper presented at the 28th Annual Conference on African Linguistics, Cornell University, July, 1997.

Ngonyani, Deogratias. 1996. "The morphosyntax of applicatives." Ph.D. dissertation, UCLA.

Ngonyani, Deogratias. 1994. "A classification of southern Tanzanian languages." MA thesis, UCLA.

Sportiche, Dominique. 1996. "Clitic constructions." In J. Rooryck and L. Zaring (eds.), Phrase Structure and the Lexicon, pp. 213-276. Dordrecht: Kluwer Academic Publishers.

Trithart, Mary L. 1983. "The applied affix and transitivity: A historical study in Bantu." Ph.D. dissertation, UCLA.

Department of Linguistics

Indiana University

Bloomington, IN 47405

dngonyan@indiana.edu
[Received January 1998; revision received May 1998; accepted June 1998] 
